Article

\title{
Orange Leafhopper Cicadulina bipunctata Feeding Induces Gall Formation Nitrogen Dependently and Regulates Gibberellin Signaling
}

\author{
Sho Miyazaki ${ }^{1, *}$, Keita Kasahara ${ }^{1}$, Soh Matsui ${ }^{1}$, Makoto Tokuda ${ }^{2}$ and Yoko Saikawa ${ }^{1, *}$ \\ 1 Faculty of Science and Technology, Keio University, 3-14-1 Hiyoshi, Kohoku-ku, Yokohama 223-8522, Japan; \\ keitakasahara@keio.jp (K.K.); atamatsuisoh@keio.jp (S.M.) \\ 2 Faculty of Agriculture, Saga University, 1 Honjo-machi, Saga 840-8502, Japan; tokudam@cc.saga-u.ac.jp \\ * Correspondence: sho0707m@keio.jp (S.M.); saikawa@applc.keio.ac.jp (Y.S.); \\ Tel.: +81-(0)-45-566-1577 (S.M.); +81-(0)-45-566-1562 (Y.S.)
}

Received: 31 August 2020; Accepted: 24 September 2020; Published: 26 September 2020

\begin{abstract}
Orange leafhopper Cicadulina bipunctata feeding induces wallaby ear symptoms, namely growth suppression and gall formation characterized by severe swelling of leaf veins, on various Poaceae, thereby leading to low crop yields. Here, we investigated the development of wallaby ear symptoms on rice seedlings due to C. bipunctata feeding. After confirming that C. bipunctata feeding induces growth suppression and gall formation on rice seedlings, we further demonstrated that gall formation score decreased with decreasing levels of nitrogen in the medium and that C. bipunctata feeding induces the expression levels of nitrogen transporter genes. These gene expression changes may participate in the nutrient accumulation observed in galled tissues and in gall formation. In addition, these expression changes should induce growth promotion but the inhibition of gibberellin signaling by C. bipunctata feeding might be the reason why growth is suppressed. Treatment with plant growth regulators did not affect gall formation, suggesting the existence of a complex gall formation mechanism by C. bipunctata feeding.
\end{abstract}

Keywords: insect feeding; gall formation; growth suppression; plant hormones; nutrient levels

\section{Introduction}

The orange leafhopper Cicadulina bipunctata (Melichar) is distributed widely across eastern and northern Africa, the Indian Ocean, the southern Palearctic, eastern Japan, namely Shikoku, Kyushu, and the Bonin Islands, and southern to northern Australia [1-3]. This species is considered a serious pest of maize, rice, and wheat because $C$. bipunctata feeding induces growth suppression and severe swelling of leaf veins (Figure 1), both of which leading to the loss of leaf and stem dry matter in maize and resulting in yield loss [4]. However, yield reductions caused by C. bipunctata feeding are low in tolerant maize at the field stage, and both growth suppression and severe swelling of leaf veins can be induced on young maize but not on maize at the fifth leaf stage or older [4]. These symptoms were previously assumed to be caused by a leafhopper-transmitted virus [5,6]. However, Ofori and Francki showed that the symptoms could be induced in maize by virus-free C. bipunctata [7], and no viruses were observed by transmission electron microscopy in the swelled leaf tissues of maize [8]. Matsumura and Tokuda established a simple method for evaluating these symptoms using the varietal resistance of maize and rice, which partially revealed the generation process of wallaby ear symptoms in maize $[9,10]$. Specifically, when C. bipunctata adults were released on a young maize seedling, growth suppression and swelling of leaf veins were evident on a new leaf extending from the seedling but not on the C. bipunctata feeding site. In addition, the symptoms did not appear when further new leaves 
were produced after the removal of C. bipunctata [11]. Therefore, the swelling of leaf veins is regarded not as a viral disease but as an insect gall caused by the chemical substance(s) secreted by insects; thus, it is now termed a "wallaby ear symptom" not "wallaby ear disease."
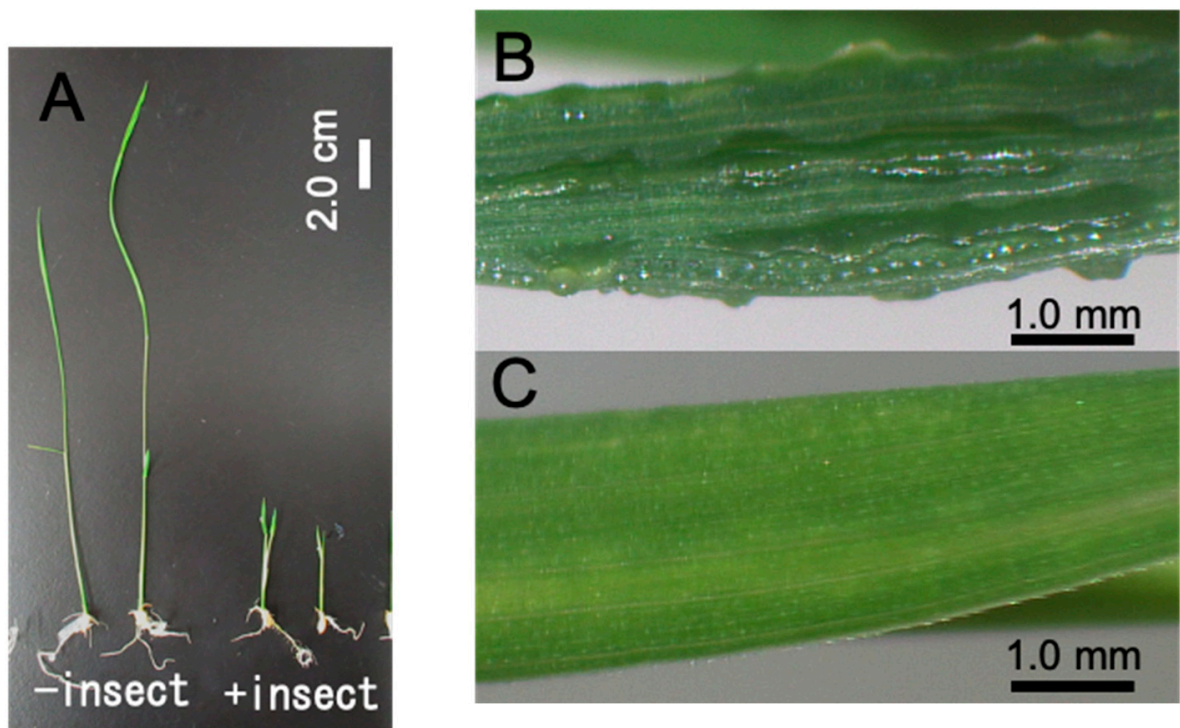

Figure 1. Wallaby ear symptoms on rice seedlings. Wallaby ear symptoms generated on rice seedlings grown on peat moss medium by the feeding of C. bipunctata. (A) Growth suppression of rice seedlings, (B) gall formation and severe swelling of leaf veins, and (C) control leaf with no C. bipunctata feeding.

Galls are structures produced by plants in response to the activity of several types of organisms, including insects. Galling insects have a close relationship with their host plants, as their habitat is largely restricted to the gall and plant organ in which the gall is developed. Three hypotheses have been proposed for the adaptive significance of gall induction: the enemy hypothesis, the nutrition hypothesis, and the microenvironment hypothesis [12]. In general, galling insects induce galls at their feeding sites and increase their own fitness. In the case of C. bipunctata, gall induction does not seem to contribute to improve their own performance because feeding and gall formation sites are different, and adults of $C$. bipunctata are able to move to other host plants in the field. Nevertheless, the amino acid levels and glucose content of galled leaves are increased by C. bipunctata feeding, and the emergence and developmental rate of nymphs also increase when they feed on galled leaves [13]. This suggests that gall tissues contribute to the improved performance of $C$. bipunctata offspring. The involvement of plant hormones in gall formation has long been suggested due to their presence in galling insects [14-19]. Cytokinins including trans-Zeatin ( $\mathrm{tZ}$ ) centrally regulate cell division and differentiation in plants and gibberellins (GAs) promote seedling elongation. In galled maize leaves, higher content of cytokinin and lower content of GAs were found than in ungalled leaves [20]. Such hormonal changes have not been observed when $C$. bipunctata was released in the leaves of wallaby ear symptom-resistant maize, indicating that plant hormones contribute to gall formation.

The present study aimed to investigate the physiological activity of wallaby ear symptom on rice due to C. bipunctata. We first examined the relationships between nutrients of plant growth medium and wallaby ear symptom, growth suppression, and gall formation. Secondly, we investigated the effect of plant hormones and its regulators on growth suppression and gall formation in rice.

\section{Results}

\subsection{Wallaby Ear Symptoms on Rice Seedlings}

Because nymphs hatched during the assay, C. bipunctata females were not suitable for the bioassay; hence, only males were used (Figure S1). We first confirmed whether the wallaby ear symptoms 
induced in rice seedlings (Nipponbare variety) were similar to that of maize seedlings [9,21]. Agar, half-strength Murashige and Skoog (MS), MS, and peat moss were used as media for the bioassay. Figure 1 shows the induction of wallaby ear symptoms, growth suppression (Figure 1A) and gall formation (Figure 1B,C) in rice seedlings using peat moss as the medium.

Figure 2 shows the results of the whole bioassay. Seedling growth was significantly suppressed by the feeding of $C$. bipunctata in all tested media (Figure $2 \mathrm{~A}, p<0.05$, Tukey's honestly significant difference (HSD) test). The two-way analysis of variance (ANOVA) revealed that both feeding of C. bipunctata and media had a statistically significant effect on seedling length, and there was an interactive effect between feeding of C. bipunctata and media (Table S2). After 10 days of cultivation, we evaluated the score of gall formation. Nutrients levels differed across media, and Tukey's HSD test demonstrated that agar, half-strength MS, and MS significantly differed from each other $(p<0.05)$ but no significant difference was observed between MS and peat moss ( $p=0.77)$. In contrast to seedling length, with increasing levels of nutrients $(1.0 \%$ agar $<$ half-strength MS $<$ MS, peat moss), gall formation by the feeding of C. bipunctata also substantially increased on the rice seedlings (Figure $2 \mathrm{~B}$ ).

A

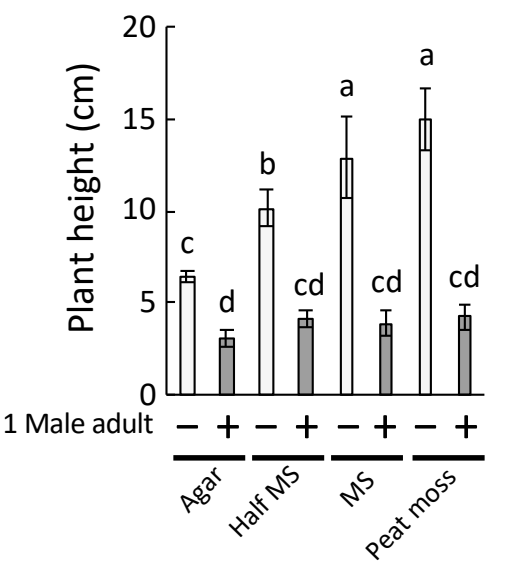

B

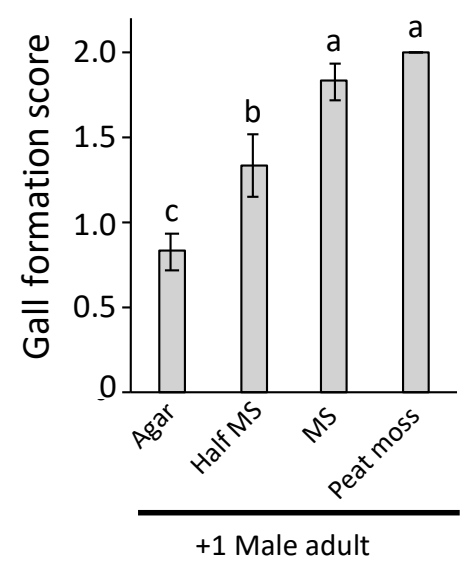

Figure 2. Effects of media on wallaby ear symptoms. Rice seedlings were transferred onto new agar, half-strength Murashige and Skoog (MS) (half MS), MS, or peat moss media with/without one C. bipunctata male. (A) Seedling length measured on day 4. Comparisons are based on two-way ANOVA (Table S2) followed by Tukey's honestly significant difference (HSD) test. Bars with different letters indicate significant differences $(p<0.05)$. Error bars indicate the standard deviation, $n=12$. (B) Gall formation score recorded on day 10. Bars with different letters indicate significant differences $(p<0.05)$ using Tukey's HSD test. Error bars indicate the standard deviation, $n=12$.

\subsection{Nitrogen Requirement for Gall Formation on Rice Seedlings}

Due to the significant difference in the generation of galls between MS and agar media, we further investigated whether gall formation depended on nutrient levels. We cultivated rice seedlings in MS media without nitrogen $(\mathrm{N})$, phosphorous $(\mathrm{P})$, potassium $(\mathrm{K})$, sulfur $(\mathrm{S})$, calcium $(\mathrm{Ca})$, magnesium $(\mathrm{Mg})$, or iron $(\mathrm{Fe})$ with or without $C$. bipunctata. Gall generation only significantly decreased in the absence of $\mathrm{N}(p<0.001$, Dunnett's test) (Figure 3A). Thus, the correlation between $\mathrm{N}$ and gall formation was further evaluated. When the $\mathrm{N}$ source $\left(\mathrm{NH}_{4} \mathrm{NO}_{3}\right.$ and $\left.\mathrm{KNO}_{3}\right)$ was reduced to $1 / 10$ and $1 / 100$ of that in the control MS medium, the gall formation score significantly decreased as $\mathrm{N}$ decreased; however, no further reduction was observed between $1 / 100$ and zero $\mathrm{N}$ ( $p=0.35$, Tukey's HSD test) (Figure 3B). In contrast, growth suppression by the feeding of $C$. bipunctata was not affected by nutrient levels (Figure S3). The two-way ANOVA revealed that feeding of C. bipunctata significantly suppressed growth in all tested conditions, but there was no interactive effect between feeding and nutrient deficiency (Table S2). Lack of N, K, or Fe led to growth inhibition compared to control seedlings under 
C. bipunctata non-feeding conditions, but no significant difference was observed among C. bipunctata feeding conditions. Considering all single macronutrient-deficient media, significant differences were observed between C. bipunctata feeding and non-feeding conditions (Figure S3).

A

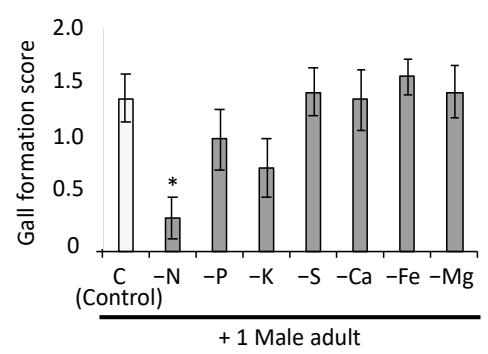

B

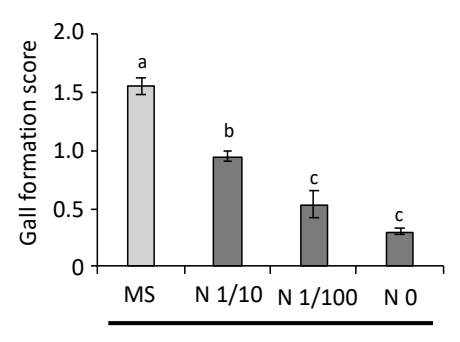

C

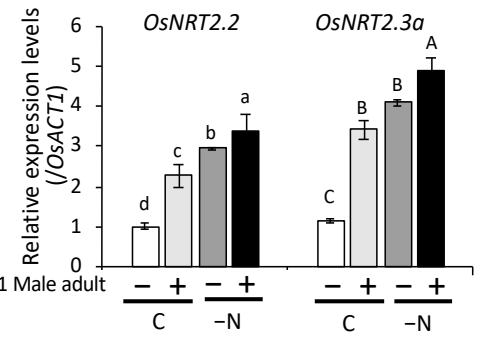

Figure 3. Effects of nutrient deficiency on gall formation. (A) Rice seedlings were transferred onto new MS media without $\mathrm{N}, \mathrm{P}, \mathrm{K}, \mathrm{S}, \mathrm{Ca}, \mathrm{Mg}$, or $\mathrm{Fe}$, and male $\mathrm{C}$. bipunctata were added. C-control. Gall formation score was recorded 10 days after samples were transferred to each type of media. Dunnett's test $\left({ }^{*}, p<0.01\right.$ versus control) was performed to evaluate differences among treatments. Error bars indicate the standard deviation, $n=16$ (-Ca and $-\mathrm{Fe})$ and $n=18(\mathrm{C},-\mathrm{N},-\mathrm{P},-\mathrm{K}-\mathrm{S}$ and $-\mathrm{Mg})$. (B) Gall formation score decreased as $\mathrm{N}$ decreased. Bars with different letters indicate significant differences $(p<0.05)$ with Tukey's HSD test. Error bars indicate the standard deviation, $n=20$ (MS and $\mathrm{N} \mathrm{1/10)}$ and $n=23$ (-N and N 1/100). (C) C. bipunctata feeding induced the expression of rice $\mathrm{N}$-acquisition gene OsNRT2.2 and $\mathrm{NO}_{3}{ }^{-}$long distance transporter gene OsNRT2.3a. C; control (MS media). Bars with different letters indicate significant differences $(p<0.05)$ with Tukey's HSD test. Error bars indicate the standard deviation, $n=3$.

Since $\mathrm{N}$ is required for gall formation, we investigated the effect of $C$. bipunctata feeding on $\mathrm{N}$-uptake- and transport-related gene expression. Nitrogen is an essential nutrient for plant growth and development and for the uptake of nitrate ions $\left(\mathrm{NO}_{3}{ }^{-}\right)$, which is mediated by nitrate transporters (NRTs). In rice, $\mathrm{NO}_{3}{ }^{-}$can be directly transported to the xylem from the root by the OsNRT2.3a transporter [22]. To determine whether N-uptake- and transport-related genes responded to $C$. bipunctata feeding, we examined gene expression levels of rice seedlings cultivated on MS or N-deficient media with or without C. bipunctata for 4 days. As shown in Figure 3C, the expression levels of the rice $\mathrm{N}$-acquisition gene OsNRT2.2 and $\mathrm{NO}_{3}{ }^{-}$long distance transporter gene OsNRT2.3a in the root were significantly increased in N-deficiency treatments $(p<0.001$, Tukey's HSD test), as reported previously [23]. Moreover, C. bipunctata feeding induced the expression of both genes even under $\mathrm{N}$-deficient conditions $(p<0.05$, Tukey's HSD test).

\subsection{Regulation of GA Signaling by C. bipunctata Feeding}

It has been reported that $C$. bipunctata feeding significantly decreased GA contents and increased cytokinin contents in extending galled leaves of maize [20]. We thus investigated whether wallaby ear symptoms in rice seedlings was regulated by GA and/or its biosynthetic inhibitor paclobutrazol (PAC). The two-way ANOVA revealed that both feeding of C. bipunctata and PAC/GA treatment had a statistically significant effect on seedling length, and there was an interactive effect between feeding of C. bipunctata and PAC/GA treatment (Table S2). As shown in Figure 4A, growth suppression by $10 \mu \mathrm{M}$ PAC was recovered by the application of $1 \mu \mathrm{M} \mathrm{GA}(p<0.001$, Tukey's HSD test) in the non-feeding condition. In the C. bipunctata feeding condition, growth was suppressed as in the $10 \mu \mathrm{M}$ PAC treatment, but it did not recover sufficiently after the application of $10 \mu \mathrm{M}$ GA. However, the growth suppression by C. bipunctata feeding was further suppressed by the application of $100 \mu \mathrm{M}$ PAC, similar to that of seedlings with $100 \mu \mathrm{M}$ PAC under C. bipunctata non-feeding conditions ( $p=0.18$, Tukey's HSD test). No significant difference was observed in gall formation occurrence regardless of the supplementation of GA or PAC (Figure 4B, one-way ANOVA, $F(2,15)=3.68, p=0.90$ ). These data showed that 
C. bipunctata feeding causes rice plants to be less responsive to GA. Therefore, we investigated the effect of $C$. bipunctata feeding on the expression of GA-biosynthetic and -catabolic rice genes. As shown in Figure $4 \mathrm{C}$, the transcript levels of the GA-biosynthetic genes OsGA20ox2 and OsGA3ox2 were significantly increased by the PAC treatment and decreased by the GA treatment, with the exception of OsGA3ox2. The transcript levels of GA-catabolic genes OsGA2ox3 and OsGA2ox4 were significantly decreased by the PAC treatment and increased by GA treatment ( $p<0.05$, Tukey's HSD test). In the C. bipunctata feeding condition, the transcript levels of the GA-biosynthetic genes were significantly increased but no significant difference was observed in GA-catabolic genes. Thus, C. bipunctata feeding not only reduced GA responsiveness, but also induced the expression of the GA biosynthetic genes.
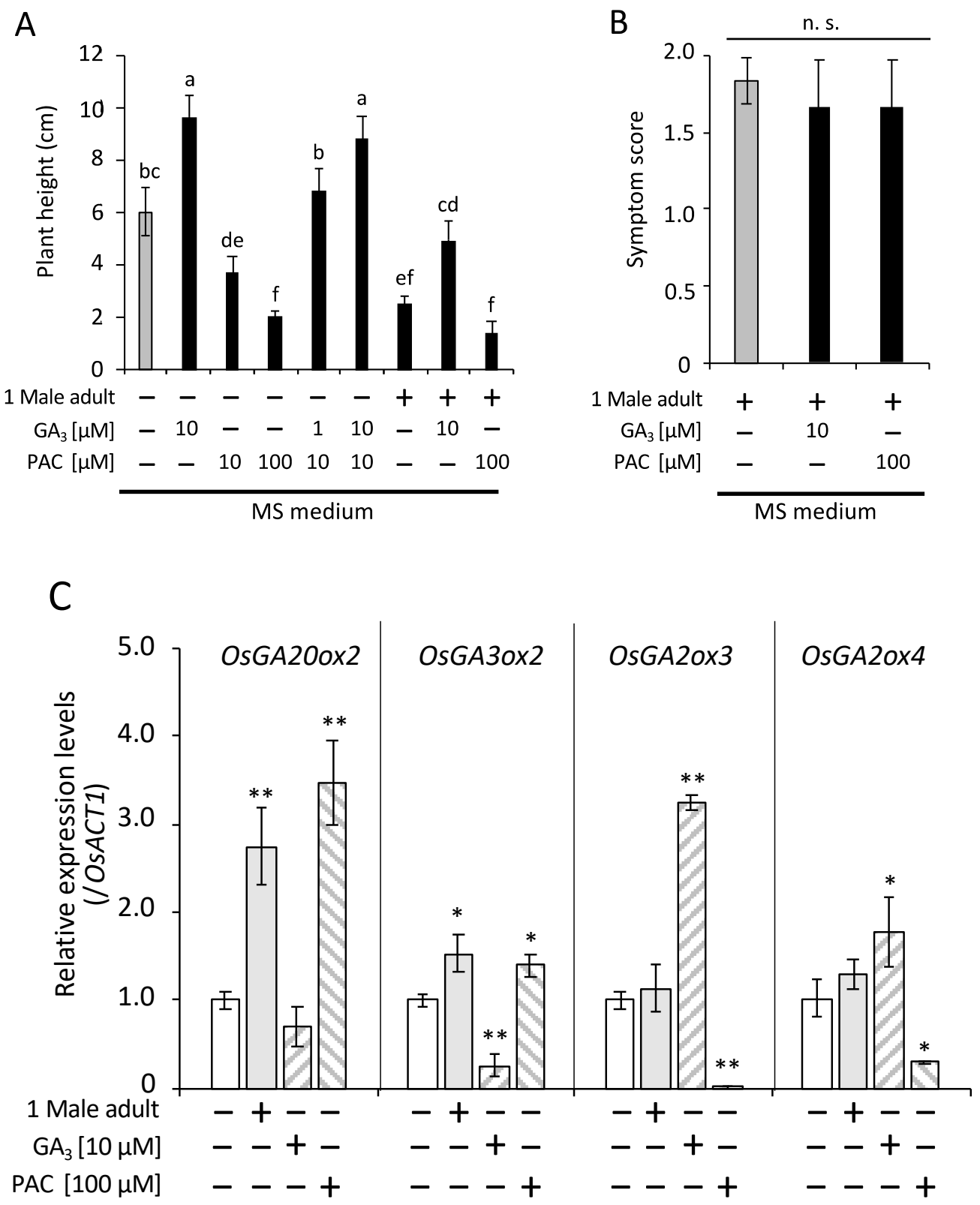

Figure 4. Effects of gibberellin (GA) signaling on wallaby ear symptoms. The rice seedlings were placed on MS containing $\mathrm{GA}_{3}$ or/and paclobutrazol (PAC) or $0.1 \%$ dimethyl sulfoxide (DMSO) as a mock control with or without a male C. bipunctata. (A) The length of seedlings was measured on day 4 and comparisons were made by two-way ANOVA followed by Tukey's HSD test. Bars with different letters indicate significant differences $(p<0.05)$. Error bars indicate the standard deviation, $n=6$. (B) The gall 
formation score was recorded 10 days after samples were transferred to each type of media. There was no significant interaction between insect feeding and PAC/GA treatment (one-way ANOVA, $F(2,15)=3.68$, $n=10, p=0.90)$. Error bars indicate the standard deviation, n. s.; not significant. (C) Transcript levels of GA-biosynthetic genes (OsGA20ox2 and OsGA3ox2) and GA-catabolic genes (OsGA2ox3 and OsGA2ox4) are relative to those of OsACT1 (used as the internal control). Dunnett's test $\left({ }^{*} p<0.05,{ }^{* *} p<0.01\right.$ versus (-)). Error bars indicate the standard deviation, $n=3$.

Next, the influence of cytokinin on wallaby ear symptoms was examined. It has been demonstrated that growth inhibition of rice seedlings by cytokinin is suppressed by the chemical regulator S-4893 through its antagonistic action on cytokinin receptors [24]. Therefore, we used this compound for the bioassay. We found that neither cytokinin $\mathrm{tZ}$ or S-4893 had a significant effect on growth or gall formation with $C$. bipunctata feeding (Figure S4). In addition to GA and $t Z$, we also investigated the effect of other plant hormones on wallaby ear symptom; however, neither brassinosteroid (BL), its inhibitor brassinazol (Brz), auxin (IAA), or its receptor antagonist $\alpha$-(phenylethyl-2-oxo)-IAA (PEO-IAA) had significant effects on growth suppression and gall formation with C. bipunctata feeding (Figures S5 and S6).

\section{Discussion}

It has been reported that $C$. bipunctata feeding induces wallaby ear symptoms, namely growth suppression and gall formation characterized by severe swelling of leaf veins, on various Poaceae including the major staple crops maize, rice, and wheat [21]. In agreement with previous studies, the present results showed that $C$. bipunctata induces both symptoms in rice seedlings $[9,21]$. In all tested media, gall formation score tended to increase as nutrient levels also increased, and a correlation was found between gall formation and $\mathrm{N}$ content. This result suggested that $\mathrm{N}$ was required for gall formation.

We also demonstrated that the expressions of genes related to $\mathrm{N}$-uptake and $\mathrm{N}$-transport were increased by $\mathrm{C}$. bipunctata feeding, even in $\mathrm{N}$-deficiency conditions. It has been reported that the expressions of OsNRT2.1 and OsNRT2.3a respond not only to nitrate concentration but also to drought stress [25]. Yang et al. reported that rice infected by the endophytic fungus Phomopsis liquidambari showed substantial changes in $\mathrm{N}$ uptake and $\mathrm{N}$ metabolism [26]. The transcript levels of $\mathrm{N}$-assimilation genes including OsNRT2.1 were higher in infected than in uninfected tissues, and the transcript levels in endophyte-infected tissue was highest under low $\mathrm{N}$ conditions. Thus, Yang et al. indicated that low $\mathrm{N}$-fertilization induces a physiological state of rice that is favorable to P. liquidambari symbiosis, and that the resulting higher infection by the fungal endophyte is necessary for the positive effects observed in rice performance [26]. C. bipunctata also increases the amino acid and glucose levels in the galled leaves of maize thereby suggesting that a $\mathrm{N}$ source is required for $\mathrm{N}$-rich galls [13]. Taken together, the results of previous studies and that or the present study suggest that $\mathrm{N}$-uptake associated with gene expression changes may participate in the nutrient accumulation observed in galled tissues, in gall formation, and in nutrient-rich food for C. bipunctata feeding. It is not clear how $\mathrm{N}$ is transported to the gall and why C. bipunctata suppress the growth of the plant they feed upon.

The mechanism of gall formation has been studied for a long time, but it is still unclear. Some insects induce galls in areas in which they do not feed, similarly to C. bipunctata [27]. In addition, the application of extracts prepared from gall-inducing insects to host plants induces morphological changes [28-30]. These findings suggest that bioactive chemical substances injected by the insects move within host tissues and influence gall formation. It has been proposed that plant hormones play important roles in gall formation and maintenance. In fact, galled maize leaves due to $C$. bipunctata feeding contain higher contents of $t Z$ and lower contents of GAs than ungalled leaves [20]. Hence, we performed a bioassay using $\mathrm{tZ}, \mathrm{GA}$, and their signal/biosynthesis inhibitors to determine whether wallaby ear symptoms are affected by these plant hormones. Notably, such treatments did not affect gall formation. Thus, information on how plant hormones are involved in gall formation is still needed to help elucidate the gall formation mechanism. The other wallaby ear symptom, growth inhibition, was affected by 
both GA and its inhibitor PAC. Growth suppression by C. bipunctata feeding was similar to that of rice seedlings treated with $10 \mu \mathrm{M}$ PAC. The rice seedlings growth suppressed by treatment with $10 \mu \mathrm{M}$ PAC was recovered by applying $1 \mu \mathrm{M}$ GA and accelerated by $10 \mu \mathrm{M} \mathrm{GA}$, whereas the growth suppression by C. bipunctata feeding did not completely compensated by applying $10 \mu \mathrm{M} \mathrm{GA}$. Moreover, C. bipunctata feeding was not significantly accelerated by the application of $100 \mu \mathrm{M}$ PAC. In addition, C. bipunctata feeding induced the expression of the two GA-biosynthetic genes tested but not that of the two GA-catabolic genes tested. Consistent with previous studies in maize [20], this gene expression pattern implies that GA content is low in plants. These results implied that GA signaling and/or GA-biosynthesis, but not GA-catabolism, was likely impaired by C. bipunctata feeding, resulting in suppressed rice growth. Recently, Yasui et al. showed that downregulation of the transcription factor OsWOX4, which regulates shoot apical meristem maintenance, induces severe defects in leaf development [31]. The chemical substance(s) injected by C. bipunctata during feeding may directly or indirectly affect the shoot apical meristem, which harbors a group of stem cells that induce growth suppression. This hypothesis needs further exploration; therefore, future research should examine the transcriptional regulation of GAs modulating the expression of OsWOX.

A previous study showed that barley does not exhibit any wallaby ear symptoms, unlike other Poaceae, and that the two symptoms could be independently suppressed by using six barley chromosome disomic addition lines [32]. However, it is still unclear whether both phenomena are regulated by a single chemical substance. That is, one or more chemical substances injected by C. bipunctata and inducing gall formation and growth inhibition may regulate the expressions of genes related to $\mathrm{N}$-uptake and transport and may inhibit GA signaling to suppress rice growth. Further studies are needed to elucidate the mechanism of wallaby ear symptoms.

\section{Materials and Methods}

\subsection{Materials and Growth Conditions}

Cicadulina bipunctata were obtained from Kyushu Okinawa Agricultural Research Center, NARO, and wild rice (Nipponbare variety; Nouken Co., Ltd., Misato, Japan) was used in all experiments (Figure S1). C. bipunctata egg-laid rice seedlings were incubated in an insect-proof cage (Asahi, Tokyo, Japan) at $28.5^{\circ} \mathrm{C}$ under an $8 \mathrm{~h} / 16 \mathrm{~h}$ dark/light cycle; nymphs were hatched after one-week incubation. For the rice seedling tray exchange, rice seeds were sterilized with sodium hypochlorite and germinated in water for $48 \mathrm{~h}$ at $28.5^{\circ} \mathrm{C}$. Germinated seeds were sown on peat moss, the fibrous product of sphagnum moss and other organic materials that decompose in peat bogs (Hokkaido Peat Moss, Saitama, Japan), in the plastic tray of the insect-proof cage and cultivated for 4 days. When renewing the rice seedling tray, the old rearing container was turned up and the new rearing container was turned upside down, which caused the insects inside to drop onto the new rice seedling tray. Rice seedling tray exchange was conducted weekly. Emerged adults were obtained after four weeks, and then laid eggs.

\subsection{Bioassay}

\subsubsection{Preparation of Rice Seedlings}

Rice seeds were sterilized for $10 \mathrm{~min}$ in $10 \%$ sodium hypochlorite and germinated in water for $48 \mathrm{~h}$ at $28.5^{\circ} \mathrm{C}$. The germinated seeds were planted in $1.0 \%(w / v)$ agar and cultivated for $48 \mathrm{~h}$ at $28.5^{\circ} \mathrm{C}$ under an $8 \mathrm{~h} / 16 \mathrm{~h}$ dark/light cycle. Germinated seedlings were used in all experiments.

\subsubsection{Effects of Plant Growth and Gall Induction by C. bipunctata on Rice Seedlings}

To examine the generation of wallaby ear symptoms by C. bipunctata, 1.0\% agar, half-strength MS medium (Nihon Seiyaku, Tokyo, Japan) with $1.0 \%(w / v)$ agar, MS medium with $1.0 \%(w / v)$ agar, and peat moss were used in the tests. Each germinated seedling was transferred onto $1.0 \%(w / v)$ agar, half MS, MS, or peat moss contained in 1.5-mL tubes. Then, each tube plus one C. bipunctata male 
was placed into a glass tube $(17.5 \times 135 \mathrm{~mm})$ with a lid containing a hole and cultivated at $28.5^{\circ} \mathrm{C}$ under an $8 \mathrm{~h} / 16 \mathrm{~h}$ dark/light cycle. A tube containing no insect was used as the control for each medium. After 4 days of cultivation, the length of seedlings was measured using ImageJ software (National Institutes of Health, Bethesda, MA, USA). After 10 days of cultivation, formed galls were observed using a microscope (Shimadzu STZ-171, Shimadzu Corp., Kyoto, Japan) and the symptom scores ( 2 = tissues heavily swollen; $1=$ veins partially thickened; $0=$ no visible symptoms) established by Matsumura and Tokuda were recorded (Figure S2) [9], $n=12$. These experiments were repeated three times with similar results.

\subsubsection{Effects of Nutrient Deficiency on Plant Growth and Gall Induction}

To evaluate the effects of nutrient levels on plant growth and gall induction, a germinated seedling was planted in the nutrient-sufficient medium (control) or in a single macronutrient deficient medium (i.e., without $\mathrm{N}, \mathrm{P}, \mathrm{K}, \mathrm{S}, \mathrm{Ca}, \mathrm{Mg}$, or Fe) with $1.0 \%(w / v)$ agar in $1.5-\mathrm{mL}$ tubes (Table S1). Then, the tubes and one $C$. bipunctata male per tube were placed into glass tubes $(17.5 \times 135 \mathrm{~mm})$ with a lid containing a hole and cultivated at $28.5^{\circ} \mathrm{C}$ under an $8 \mathrm{~h} / 16 \mathrm{~h}$ dark/light cycle. A tube containing no insect was used as the control. All media contained $1 \mathrm{mM}$ 2-( $\mathrm{N}$-morpholino) ethanesulfonic acid buffer ( $\mathrm{pH}$ 5.7) [33]. Four days later, the length of seedlings was measured, $n=5$. Symptom scores were recorded after 10 days of cultivation, as described above, $n=16$ (-Ca and $-\mathrm{Fe}$ ) and $n=18$ (C, $-\mathrm{N},-\mathrm{P},-\mathrm{K}-\mathrm{S}$ and $-\mathrm{Mg})$. These experiments were repeated three times with similar results.

\subsubsection{Effects of Plant Hormones on Plant Growth and Gall Induction}

To examine the effect of plant hormones on plant growth and gall induction, seedlings were planted in MS agar medium with 1.0\% $(w / v)$ plant hormones and its regulators, i.e., GA 3 (FUJIFILM Wako Pure Chemical Corporation, Osaka, Japan), PAC (FUJIFILM Wako Pure Chemical Corporation, Tokyo, Japan), cytokinin-signaling inhibitor S-4893 (Enamine Ltd., Ukraine) [24], cytokinin tZ (FUJIFILM Wako Pure Chemical Corporation), auxin (IAA, FUJIFILM Wako Pure Chemical Corporation), IAA receptor inhibitor (PEO-IAA, Med Chem Express, NJ, USA) [34], brassinolide (BL, Cayman Chemical Company, MI, USA), BL biosynthesis inhibitor brassinazol (Brz, Cayman Chemical Company), or dimethyl sulfoxide (DMSO) as a mock control, and cultivated at $28.5^{\circ} \mathrm{C}$ under an $8 \mathrm{~h} / 16 \mathrm{~h}$ dark/light cycle with or without one male adult of $C$. bipunctata. Four days later, the length of seedlings was measured, $n=6$ (PAC/GA, tZ/S4893 and IAA/PEO-IAA) and $n=5$ (BL/Brz). Symptom scores were recorded after 10 days of cultivation, as described above, $n=10$ (PAC/GA) and $n=5$ (tZ/S4893, IAA/PEO-IAA and $\mathrm{BL} / \mathrm{Brz})$. These experiments were repeated three times with similar results.

\subsubsection{Preparation of the Samples for Quantitative Real-Time PCR}

To examine the effects of $C$. bipunctata feeding on the expressions of genes related to N-uptake and transport, a germinated seedling was transferred onto MS medium or N-deficient MS medium in 1.5-mL tubes. Then, the tubes and one C. bipunctata male per tube were placed into glass tubes $(17.5 \times 135 \mathrm{~mm})$ with a lid containing a hole and cultivated for 4 days at $28.5^{\circ} \mathrm{C}$ under continuous light. A tube containing no insect was used as the control. To examine the effects of $C$. bipunctata feeding on GA-related gene expression, a germinated seedling was transferred onto MS medium containing $\mathrm{GA}_{3}$, PAC, or $0.1 \%$ DMSO as mock control in $1.5-\mathrm{mL}$ tubes. Then, the tubes and one C. bipunctata male per tube were placed into glass tubes $(17.5 \times 135 \mathrm{~mm})$ with a lid containing a hole and cultivated for 4 days at $28.5^{\circ} \mathrm{C}$ under an $8 \mathrm{~h} / 16 \mathrm{~h}$ dark/light cycle. A tube containing no insect was used as the control.

\subsection{Quantitative Real-Time PCR Analysis}

Total RNA was extracted from frozen plant material using PureLink Plant RNA Reagent (Invitrogen, Life Technologies, CA, USA) according to the manufacturer's instructions. Five hundred nanograms of each RNA sample was used for cDNA synthesis with the ReverTra Ace ${ }^{\circledR}$ qPCR RT Master Mix (TOYOBO, Tokyo, Japan). Quantitative real-time PCR was performed as described previously [35]. Three identically 
treated replicates of each RNA sample were analyzed to account for biological variation, $n=3$. The primers for genes OsACT1 (encoding actin1), OsGA20ox2 (encoding GA20-oxidase 2, LOC_Os01g66100), OsNRT2.2 (LOC_Os02g02190), and OsNRT2.3a (LOC_Os01g50820) were used as described previously [36-38]. OsGA2ox3 (encoding GA2-oxidase 3, LOC_Os01g55240), OsGA2ox4 (encoding GA2-oxidase 4, LOC_Os05g43880), and OsGA3ox2 (encoding GA -oxidase 2, LOC_Os01g08220) were amplified with the following primers: OsGA2ox3-forward (5'-TTCTTCGTCAACGTCGGCGACTCGTTGC-3') and -reverse (5'-TCTCAAACTGGGCCAGCCTGTTGTCTCC-3'); OsGA2ox4-forward (5'-GCGTGCGAGAGGTTT GGGTTCTTCAAGG-3') and -reverse (5'-CTCCGCCACCATCTCCAGCACCGTCC-3'); OsGA3ox2forward (5'-TCCTCCTTCTTCTCCAAGCTCAT - $\left.3^{\prime}\right)$ and -reverse (5'-GAAACTCCTCCATCACGTCA CA-3'). The quantitative real-time PCR experiment was repeated two times with similar results.

\subsection{Statistical Analyses}

All data are shown as means \pm standard deviations. Statistical analyses, Tukey's HSD test, and Dunnett's test were performed using the R software (https://www.r-project.org/).

\subsubsection{Plant Growth}

To examine the effects of C. bipunctata feeding on plant growth, a two-way ANOVA followed by Tukey's HSD test were used to evaluate significant differences among C. bipunctata feeding and plant growth media or GA/PAC treatments. For all tests, $p<0.05$. To evaluate C. bipunctata feeding effects on plant growth, a two-way ANOVA followed by Dunnett's test was applied to examine differences between $C$. bipunctata feeding and single-nutrient deficiency. For all tests, significance was assessed at levels of $p<0.05$ and $p<0.01$. A two-sided Student's $t$-test was conducted to determine significant differences in seedling length between C. bipunctata feeding and non-feeding treatments.

\subsubsection{Gall Formation}

To examine the effect of $C$. bipunctata feeding on gall formation score, a Tukey's HSD test was used to evaluate significant differences between C. bipunctata feeding and plant growth media treatments. For all tests, $p<0.05$. The Dunnett's test was applied to examine differences between C. bipunctata feeding and nutrient deficiency. For all tests, $p<0.01$. To examine $C$. bipunctata feeding effects on the expression levels of N-uptake and transport genes, we used Tukey's HSD multiple comparison test. To examine the C. bipunctata feeding effects on the expression levels of GA-biosynthesis and -catabolic genes, we used Dunnett's multiple comparison test. In these tests, $p<0.05$ and $p<0.01$. To assess the effects of plant growth regulators on gall formation, a one-way ANOVA was performed.

Supplementary Materials: The following are available online at http://www.mdpi.com/2223-7747/9/10/1270/s1, Figure S1: Life cycle of C. bipunctata, Figure S2: Scoring of gall formation, Figure S3: Effects of nutrient deficiency on seedling length, Figures S4-S6: Effects of plant hormone signaling on wallaby ear symptoms, Table S1: Culture media used to investigate effects of nutrient deficiency, Table S2: Statistical analyses.

Author Contributions: Conceptualization, S.M. (Sho Miyazaki); validation, S.M. (Sho Miyazaki), M.T. and Y.S.; investigation, S.M. (Sho Miyazaki), K.K. and S.M. (Soh Matsui); writing-original draft preparation, S.M. (Sho Miyazaki); writing-review and editing, M.T. and Y.S.; project administration, S.M. (Sho Miyazaki); funding acquisition, S.M. (Sho Miyazaki). All authors have read and agreed to the published version of the manuscript.

Funding: This work was partially supported by Japan Society for the Promotion of Science KAKENHI Grant Number 19K15759 (Sho Miyazaki), the Pesticide Science Society of Japan (Sho Miyazaki), and Keio Gijuku Academic Development Funds (Sho Miyazaki).

Acknowledgments: We thank the Kyushu Okinawa Agricultural Research Center, NARO, for providing the C. bipunctata strain.

Conflicts of Interest: The authors declare no conflict of interest. 


\section{References}

1. Wilson, M.R.; Claridge, M.F. Handbook for the identification of leafhoppers and planthoppers of rice. Handb. Identif. Leafhoppers Planthoppers Rice 1991. [CrossRef]

2. Matsukura, K.; Matsumura, M.; Takeuchi, H.; Endo, N.; Tokuda, M. Distribution, host plants, and seasonal occurrence of the maize orange leafhopper, Cicadulina bipunctata (Melichar) (Homoptera: Cicadellidae), in Japan. Appl. Entomol. Zool. 2009, 44, 207-214. [CrossRef]

3. Kumashiro, S.; Matsukura, K.; Ogawa, R.; Matsumura, M.; Tokuda, M. Occurrence of Cicadulina bipunctata (Hemiptera: Cicadellidae) in southwestern shikoku, Japan and comparisons of gall-inducing ability between kyushu and shikoku populations. Appl. Entomol. Zool. 2014, 49, 325-330. [CrossRef]

4. Matsukura, K.; Matsumura, M. Cultural control of leafhopper-induced maize wallaby ear symptom in forage maize via early planting dates. Crop. Prot. 2010, 29, 1401-1405. [CrossRef]

5. Maramorosch, K.; Calica, C.A.; Agati, J.A.; Pableo, G. Further studies on the maize and rice leaf galls induced by Cicadulina bipunctella. Entomol. Exp. Appl. 1961, 4. [CrossRef]

6. Grylls, N.E. Leafhopper Transmission of a virus causing maize wallaby ear disease. Ann. Appl. Biol. 1975, 79, 283-296. [CrossRef] [PubMed]

7. Ofori, F.A.; Francki, R.I.B. Evidence that maize wallaby ear disease is caused by an insect toxin. Ann. Appl. Biol. 1983, 103, 185-189. [CrossRef]

8. Ohata, S. The occurence of maize wallaby ear disease caused by the feeding of leafhopper, Cicadulina bipunctata Melichar (Homoptera, Cicadellidae). J. Jpn. Soc. Grassl. Sci. 1993, 39, 120-123. [CrossRef]

9. Matsumura, M.; Tokuda, M. A mass rearing method using rice seedlings for the maize orange leafhopper Cicadulina bipunctata (Melichar) (Homoptera: Cicadellidae) and a simple method for evaluating varietal resistance of maize to maize wallaby ear disease. Kyushu Plant Prot. Res. 2004, 50, 35-39. [CrossRef]

10. Tokuda, M.; Matsumura, M. Effect of temperature on the development and reproduction of the maize orange leafhopper Cicadulina bipunctata (Melichar) (Homoptera: Cicadellidae). Appl. Entomol. Zool. 2005, 40, 213-220. [CrossRef]

11. Matsukura, K.; Matsumura, M.; Tokuda, M. Host manipulation by the orange leafhopper Cicadulina bipunctata: Gall induction on distant leaves by dose-dependent stimulation. Naturwissenschaften 2009, 96, 1059-1066. [CrossRef] [PubMed]

12. Stone, G.N.; Schönrogge, K. The adaptive significance of insect gall morphology. Trends Ecol. Evol. 2003, 18, 512-522. [CrossRef]

13. Matsukura, K.; Matsumura, M.; Tokuda, M. Host feeding by an herbivore improves the performance of offspring. Evol. Biol. 2012, 39, 341-347. [CrossRef]

14. Mapes, C.C.; Davies, P.J. Indole-3-acetic acid and ball gall development on Solidago altissima. New Phytol. 2001, 151, 195-202. [CrossRef]

15. Mapes, C.C.; Davies, P.J. Cytokinins in the ball gall of Solidago altissima and in the gall forming larvae of Eurosta solidaginis. New Phytol. 2001, 151, 203-212. [CrossRef]

16. Straka, J.R.; Hayward, A.R.; Emery, R.J.N. Gall-inducing Pachypsylla celtidis (Psyllidae) infiltrate hackberry trees with high concentrations of phytohormones. J. Plant Interact. 2010, 5, 197-203. [CrossRef]

17. Dorchin, N.; Hoffmann, J.H.; Stirk, W.A.; Novak, O.; Strnad, M.; Van Staden, J. Sexually dimorphic gall structures correspond to differential phytohormone contents in male and female wasp larvae. Physiol. Entomol. 2009, 34, 359-369. [CrossRef]

18. Yamaguchi, H.; Tanaka, H.; Hasegawa, M.; Tokuda, M.; Asami, T.; Suzuki, Y. Phytohormones and willow gall induction by a gall-inducing sawfly. New Phytol. 2012, 196, 586-595. [CrossRef]

19. Takei, M.; Yoshida, S.; Kawai, T.; Hasegawa, M.; Suzuki, Y. Adaptive significance of gall formation for a gall-inducing aphids on Japanese elm trees. J. Insect Physiol. 2015, 72, 43-51. [CrossRef]

20. Tokuda, M.; Jikumaru, Y.; Matsukura, K.; Takebayashi, Y.; Kumashiro, S.; Matsumura, M.; Kamiya, Y. Phytohormones related to host plant manipulation by a gall-inducing leafhopper. PLOS ONE 2013, 8. [CrossRef]

21. Matsukura, K.; Matsumura, M. Ecology of the maize orange leafhopper, Cicadulina bipunctata (Melichar) (Hemiptera: Cicadellidae). Jpn. Agric. Res. Q. 2013, 47, 365-369. [CrossRef] 
22. Tang, Z.; Fan, X.; Li, Q.; Feng, H.; Miller, A.J.; Shen, Q.; Xu, G. Knockdown of a rice stelar nitrate transporter alters long-distance translocation but not root influx. Plant Physiol. 2012, 160, 2052-2063. [CrossRef] [PubMed]

23. Takehisa, H.; Sato, Y.; Antonio, B.A.; Nagamur, Y. Global transcriptome profile of rice root in response to essential macronutrient deficiency. Plant Signal. Behav. 2013, 8, e24409. [CrossRef] [PubMed]

24. Arata, Y.; Nagasawa-Iida, A.; Uneme, H.; Nakajima, H.; Kakimoto, T.; Sato, R. The phenylquinazoline compound S-4893 is a non-competitive cytokinin antagonist that targets Arabidopsis cytokinin receptor CRE1 and promotes root growth in Arabidopsis and rice. Plant Cell Physiol. 2010, 51, 2047-2059. [CrossRef] [PubMed]

25. Chen, J.; Qi, T.; Hu, Z.; Fan, X.; Zhu, L.; Iqbal, M.F.; Yin, X.; Xu, G.; Fan, X. OsNAR2.1 positively regulates drought tolerance and grain yield under drought stress conditions in rice. Front. Plant Sci. 2019, 10. [CrossRef] [PubMed]

26. Yang, B.; Wang, X.M.; Ma, H.Y.; Jia, Y.; Li, X.; Dai, C.C. Effects of the fungal endophyte Phomopsis liquidambari on nitrogen uptake and metabolism in rice. Plant Growth Regul. 2014, 73, 165-179. [CrossRef]

27. Sopow, S.L.; Shorthouse, J.D.; Strong, W.; Quiring, D.T. Evidence for long-distance, chemical gall induction by an insect. Ecol. Lett. 2003, 6, 102-105. [CrossRef]

28. Martin, J.P. Stem Galls of Sugar-Cane Induced with Insect Extracts. Science 1942, 96, 39. [CrossRef]

29. Leatherdale, D. Plant Hyperplasia Induced with a Cell-Free Insect Extract. Nature 1955, 175, 553-554. [CrossRef]

30. McCalla, D.R.; Genthe, M.K.; Hovanitz, W. Chemical Nature of an Insect Gall Growth-Factor. Plant. Physiol. 1962, 37, 98-103. [CrossRef]

31. Yasui, Y.; Ohmori, Y.; Takebayashi, Y.; Sakakibara, H.; Hirano, H.-Y. WUSCHEL-RELATED HOMEOBOX4 acts as a key regulator in early leaf development in rice. PLoS Genet. 2018, 14, e1007365. [CrossRef]

32. Kumashiro, S.; Matsukura, K.; Kawaura, K.; Matsumura, M.; Ogihara, Y.; Tokuda, M. Effect of barley chromosome addition on the susceptibility of wheat to feeding by a gall-inducing leafhopper. Naturwissenschaften 2011, 98, 983-987. [CrossRef] [PubMed]

33. Shindo, M.; Shimomura, K.; Yamaguchi, S.; Umehara, M. Upregulation of DWARF27 is associated with increased strigolactone levels under sulfur deficiency in rice. Plant Direct 2018, 2, e00050. [CrossRef] [PubMed]

34. Hayashi, K.I.; Neve, J.; Hirose, M.; Kuboki, A.; Shimada, Y.; Kepinski, S.; Nozaki, H. Rational design of an auxin antagonist of the SCF TIR1 auxin receptor complex. ACS Chem. Biol. 2012, 7, 590-598. [CrossRef] [PubMed]

35. Miyazaki, S.; Kurisu, H.; Nakata, M.; Saikawa, Y. Identification of a Cyanidin-3-O- $\beta$-Galactoside in Gall Tissue Induced by Midges on Japanese Beech (Fagus crenata Blume). Biosci. Biotechnol. Biochem. 2020, 84, 797-799. [CrossRef] [PubMed]

36. Miyazaki, S.; Jiang, K.; Kobayashi, M.; Asami, T.; Nakajima, M. Helminthosporic acid functions as an agonist for gibberellin receptor. Biosci. Biotechnol. Biochem. 2017, 81, 2152-2159. [CrossRef]

37. Yang, W.; Yoon, J.; Choi, H.; Fan, Y.; Chen, R.; An, G. Transcriptome analysis of nitrogen-starvation-responsive genes in rice. BMC Plant Biol. 2015, 15, 31. [CrossRef]

38. Wang, W.; Hu, B.; Yuan, D.; Liu, Y.; Che, R.; Hu, Y.; Ou, S.; Liu, Y.; Zhang, Z.; Wang, H.; et al. Expression of the nitrate transporter gene OsNRT1.1A/ OsNPF6.3 confers high yield and early maturation in rice. Plant Cell 2018, 30, 638-651. [CrossRef]

(C) 2020 by the authors. Licensee MDPI, Basel, Switzerland. This article is an open access article distributed under the terms and conditions of the Creative Commons Attribution (CC BY) license (http://creativecommons.org/licenses/by/4.0/). 